\title{
When probabilistic seismic hazard climbs volcanoes: the Mt. Etna case, Italy - Part 2: Computational implementation and first results
}

\author{
Laura Peruzza $^{1}$, Raffaele Azzaro ${ }^{2}$, Robin Gee ${ }^{1,5}$, Salvatore D'Amico $^{2}$, Horst Langer ${ }^{2}$, Giuseppe Lombardo ${ }^{3}$,

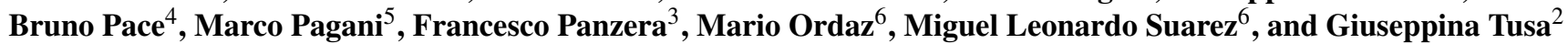 \\ ${ }^{1}$ Istituto Nazionale di Oceanografia e di Geofisica Sperimentale - OGS, 34010 Sgonico (TS), Italy \\ ${ }^{2}$ Istituto Nazionale di Geofisica e Vulcanologia (INGV), 95123 Sezione di Catania - Osservatorio Etneo, Italy \\ ${ }^{3}$ Dept. of Biological, Geological and Environmental Science, University of Catania, 95129 Catania, Italy \\ ${ }^{4}$ DiSPUTer, University “G. d'Annunzio" Chieti-Pescara, 66013 Chieti, Italy \\ ${ }^{5}$ GEM Foundation, 27100 Pavia, Italy \\ ${ }^{6}$ UNAM, 04510 Coyoacan, CDMX, Mexico
}

Correspondence to: Laura Peruzza (lperuzza@inogs.it)

Received: 30 March 2017 - Discussion started: 5 April 2017

Revised: 20 September 2017 - Accepted: 24 September 2017 - Published: 22 November 2017

\begin{abstract}
This paper describes the model implementation and presents results of a probabilistic seismic hazard assessment (PSHA) for the Mt. Etna volcanic region in Sicily, Italy, considering local volcano-tectonic earthquakes. Working in a volcanic region presents new challenges not typically faced in standard PSHA, which are broadly due to the nature of the local volcano-tectonic earthquakes, the cone shape of the volcano and the attenuation properties of seismic waves in the volcanic region. These have been accounted for through the development of a seismic source model that integrates data from different disciplines (historical and instrumental earthquake datasets, tectonic data, etc.; presented in Part 1, by Azzaro et al., 2017) and through the development and software implementation of original tools for the computation, such as a new ground-motion prediction equation and magnitude-scaling relationship specifically derived for this volcanic area, and the capability to account for the surficial topography in the hazard calculation, which influences source-to-site distances. Hazard calculations have been carried out after updating the most recent releases of two widely used PSHA software packages (CRISIS, as in Ordaz et al., 2013; the OpenQuake engine, as in Pagani et al., 2014). Results are computed for short- to mid-term exposure times (10\% probability of exceedance in 5 and 30 years, Poisson and time dependent) and spectral amplitudes of engineering interest. A preliminary exploration of the impact of sitespecific response is also presented for the densely inhabited
\end{abstract}

Etna's eastern flank, and the change in expected ground motion is finally commented on. These results do not account for $M>6$ regional seismogenic sources which control the hazard at long return periods. However, by focusing on the impact of $M<6$ local volcano-tectonic earthquakes, which dominate the hazard at the short- to mid-term exposure times considered in this study, we present a different viewpoint that, in our opinion, is relevant for retrofitting the existing buildings and for driving impending interventions of risk reduction.

\section{Introduction}

It is well known that volcanoes and earthquakes are associated everywhere, although volcanic seismicity is extremely diversified and is associated with a variety of volcanic processes (Zobin, 2012). In some active volcanic zones, namely the most populated ones, these earthquakes may cause severe damage to buildings and lifelines, representing a further source of hazard in addition to the ones posed by the eruptive activity (e.g., Zobin, 2001). Some major worldwide examples of M6-M7 earthquakes in different volcanic environments are from Japan, Indonesia, Hawaii and the Azores islands (Abe, 1979; Yokoyama, 2001), whilst in mainland Europe the Mt. Etna volcano represents a case where lowmagnitude events produce local effects of high intensity (Az- 
zaro, 2004; Azzaro et al., 2013). Since seismic hazard is associated with expected earthquakes, why can we not usually pinpoint volcanoes on a hazard map? In general, the effects of volcanic earthquakes can be overshadowed by the stronger tectonic regional earthquakes, particularly when long exposure periods are considered. Furthermore, due to their low magnitudes and the high attenuation typically exhibited in volcanic regions, most ground-motion prediction equations (GMPE) are not applicable for such events. We faced these challenges, among others, in the seismic hazard study of Mt. Etna, one of the most active volcanoes in a long-lasting inhabited area in the Mediterranean. In a few kilometers it is possible to walk from the ancient Greek and Roman archaeological remains of the coast to hostile and deserted summit craters $3.3 \mathrm{~km}$ above sea level (a.s.l.). While catastrophic earthquakes and tsunamis occur in eastern Sicily on average every 3-4 centuries (Azzaro et al., 1999), building collapse, casualties and road interruptions due to shallow, light-to-moderate earthquakes (M4-M5) happen much more frequently on the flanks of Mt. Etna (e.g., D'Amico et al., 2016). These earthquakes are linked to surficial fault sources that breathe with the tectonic stresses and the volcanic dynamics.

In recent years, several analyses have been undertaken to estimate the short- to mid-term (5-30 years) capability of local faults on Mt. Etna to generate damaging or destructive earthquakes. Two main approaches have been explored. The first is a probabilistic seismic hazard assessment (PSHA) based on macroseismic data, which uses a historical probabilistic approach (the "site-intensity approach"; see Azzaro et al., 2008, 2016) to determine the localities prone to high seismic hazard at the local scale. The second is a seismotectonic approach, where historical inter-event times of fault ruptures are investigated and used to generate an earthquake rupture forecast (Azzaro et al., 2012, 2013). In this approach, both Poissonian occurrence probabilities of major earthquakes and time-dependent occurrence probabilities using a renewal processes that takes into account the time elapsed since the last event have been determined. Both approaches have found that the local faults significantly contribute to the seismic hazard at Mt. Etna with respect to the larger tectonic structures, when short investigation times are considered.

In 2012 a new project started, namely the DPC-INGV V3 project (Azzaro and De Rosa, 2016), with one of its targets being a new PSHA for the Etna region due to local volcano-tectonic earthquakes. Working in the Mt. Etna region presents new challenges not usually faced in standard PSHA. These are due to (i) the nature of the local volcanotectonic earthquakes, which are low-magnitude (partially out of the applicability range of most GMPEs) and have large ruptures compared to those predicted by commonly used magnitude scaling relationships (MSR); (ii) the cone shape of the volcano, where events are located within the volcanic edifice above the sea level and therefore the topogra- phy (elevation) of Mt. Etna must be considered, which in turn affects source-to-site distances in the hazard computation; (iii) the attenuation properties of seismic waves in the Mt. Etna region, where shaking exhibits a rapid attenuation particularly at high frequencies; and finally (iv) the heterogeneities in rock properties within the volcanic body, so that proxies simply based on slope or surface geological mapping are not adequate to represent reliable site-specific effects. To address these challenges, we used two PSHA software packages (CRISIS, as in Ordaz et al., 2013; the OpenQuake engine, as in Pagani et al., 2014) and developed new software functionalities to incorporate the topographic surface into the hazard calculation by modeling sources and sites above the sea level. We also derived new empirical relationships specifically for Mt. Etna, such as a MSR (described more in detail in the companion paper, Azzaro et al., 2017, hereinafter referred to as Part 1), and a GMPE presented here. In this paper we summarize the source model, discuss the model implementation, new GMPE and software functionalities, and finally present the hazard results. We hope the results of this study may be integrated into a more traditional, national regulation framework (e.g., Stucchi et al., 2011) with realistic and useful ground-motion prediction maps devoted to urban planners and structural designers.

\section{Seismic source model: conceptual components}

The seismic source modeling at Mt. Etna accounts for three different levels of increasing complexity, and sources are modeled using distributed seismicity as well as faults. The source model accounts for some basic assumptions behind the physical processes driving earthquake occurrences, which in our volcanic area refer to the brittle failure of rocks under tectonic stress producing volcano-tectonic earthquakes along well-known surface rupturing faults. In particular: (i) the damaging earthquakes at Mt. Etna feature very shallow foci; (ii) these shocks, which are mainly concentrated on the southeastern flank of Mt. Etna, occur with about decennial frequency (see, for example, Azzaro et al., 2012, 2013; Sicali et al., 2014) with or without synchronous volcanic activities; (iii) the last major events and interseismic periods have been monitored by a dense, high-quality instrumental local network whose geometry and characteristics have essentially remained unchanged during in the last 2 decades (Alparone et al., 2015).

For a full description of the individual model components and the process of defining seismic sources, we refer the reader to Part 1. Different seismic sources were defined for representing the shallow volcano-tectonic seismicity at Mt. Etna, after checking that a few years of high-quality seismic monitoring, during an interseismic period, can be representative of the long-term seismic rates of the volcanotectonic faults; this simplification is supported by about 2 centuries of detailed field observations and chronicles, de- 

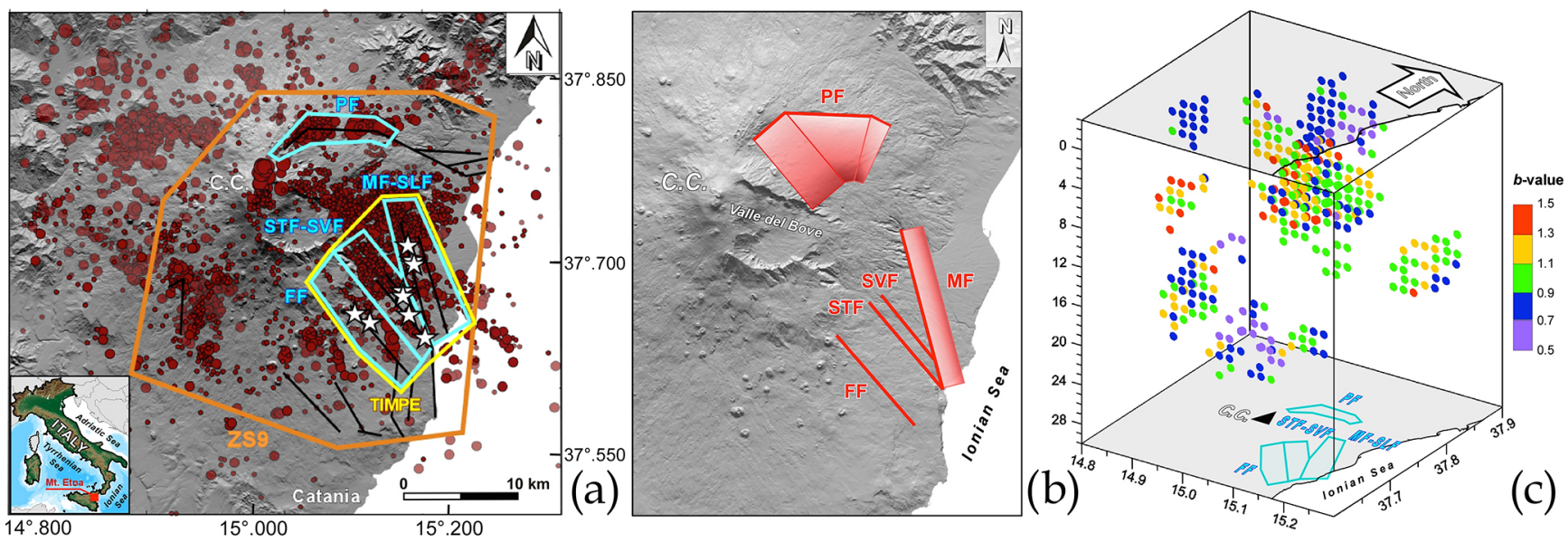

Figure 1. Source typologies at Mt. Etna. (a) Polygonal area sources representing uniform seismicity: the ones defined in this study (in pale blue and yellow) follow the seismogenic sections of the best-known fault systems; in orange is the single area source used in the map of Italian regulation (ZS9, Stucchi et al., 2011). (b) Fault sources modeling the main volcano-tectonic structures detected on Etna's flanks (see Table 1 for the nomenclature): the red boxes and lines represent the projection at the surface of the fault planes. (c) Three-dimensional mesh of point sources, used to model the scattered background seismicity, with $b$ values represented by colors. Details are given in Part 1 (Azzaro et al., 2017).

Table 1. Parameters of area seismic sources used in the final computations.

\begin{tabular}{llccrcc}
\hline $\begin{array}{l}\text { Seismic } \\
\text { zone }\end{array}$ & Faults & $\begin{array}{c}\text { Depth } \\
\text { (upper/lower) }\end{array}$ & $\begin{array}{c}b \text { value/ } \\
\beta\end{array}$ & $\begin{array}{c}a \text { value/ } \\
a_{M_{\min }}\end{array}$ & $M_{\min }^{2}$ & $M_{\max }$ \\
\hline FF & Fiandaca & $-1.0 / 1.0$ & $0.84 \pm 0.15 / 1.934$ & $1.72 /-0.38$ & 2.5 & 4.6 \\
STF-SVF & S. Tecla and S. Venerina & $-1.0 / 5.0$ & $1.13 \pm 0.16 / 2.602$ & $2.73 /-0.09$ & 2.5 & 5.2 \\
MF-SLF & Moscarello and S. Leonardello & $-1.0 / 5.0$ & $0.91 \pm 0.08 / 2.095$ & $2.51 / 0.23$ & 2.5 & 4.9 \\
PF & Pernicana & $-1.0 / 1.0$ & $0.64 \pm 0.06 / 1.474$ & $2.08 / 0.48$ & 2.5 & 4.7 \\
Timpe & & $-1.0 / 5.0$ & $0.92 \pm 0.06 / 2.118$ & $2.90 / 0.60$ & & \\
\hline
\end{tabular}

${ }^{1}$ Negative depth means above the sea level. ${ }^{2}$ The ground motion out of the range $3.0<M_{1}<4.3$ is extrapolated.

scribing the seismotectonic evidence, and by the more recent deformation rates derived from geodetic measurements. We accept this working hypothesis and thus parameterize seismic sources by extrapolating decennial datasets. We can also model by means of point sources faults that are still "unknown" as they are not recognized at the surface, and compute earthquake probabilities using any time/magnitudefrequency distribution (FMD), thus abandoning the requirements of independence and stationarity of events needed by the Poisson process.

The seismic sources considered at Mt. Etna take into account the huge amount of available geological, historical, seismological and geodetic data. The three types of seismic sources depicted in Part 1 are as follows (see Fig. 1 and concept scheme in Fig. 2):

- Area seismic sources (Fig. 1a) are zones of distributed (i.e., uniform) seismicity. These encompass the bestknown fault systems on the Mt. Etna's flanks. They are defined in both CRISIS and the OpenQuake engine by a horizontal planar surface, modeled as a series of point sources with spatially extended ruptures. This approach is the same used by the current seismic hazard map of Italian regulation (MPS04, Stucchi et al., 2011), where the whole volcanic body is enveloped in a single polygonal area.

- Fault sources (Fig. 1b) model the main tectonic structures. The geometries are based on surface ruptures and other geological and geophysical investigations. Faults are modeled in the OpenQuake engine by a mesh of points defined by top and bottom (and optionally middle) edges, whose 3-D geometry may change in dip and width and extended ruptures float along strike. In CRISIS, faults are represented by planes of given coordinate vertexes.

- Point sources (Fig. 1c) are used to represent distributed (i.e., gridded, nonuniform) seismicity. The distributed seismicity is defined in the same way by CRISIS and the OpenQuake engine, using point sources with spatially 


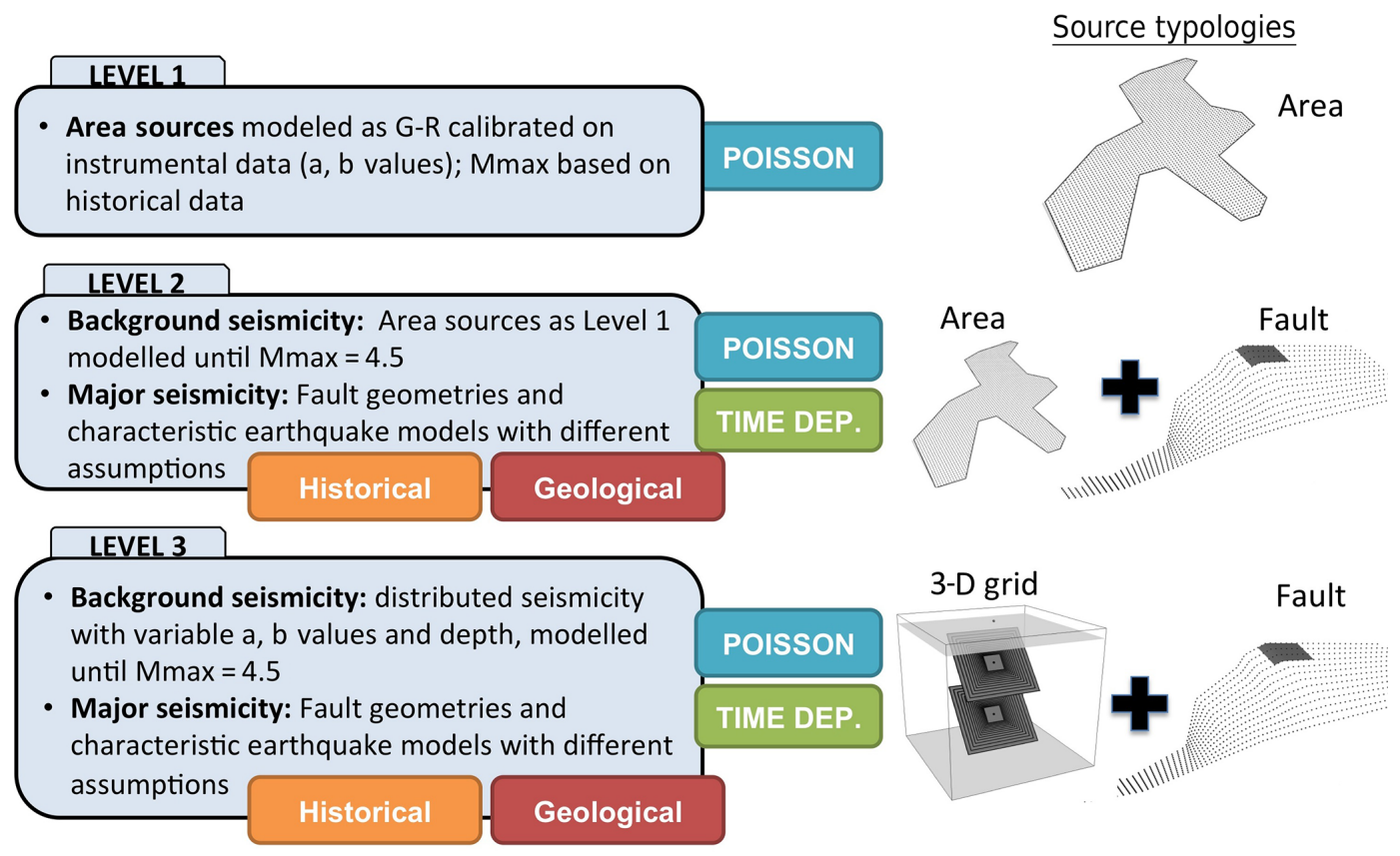

Figure 2. Schematic chart describing the three branching levels of the source model and depiction of the different source typologies used for modeling. The major seismicity of levels 2 and 3 is modeled using fault sources, where seismicity rates are derived using historical and geological approaches, considering both time independence (Poisson) and time dependence.

extended ruptures and variable properties (e.g., seismicity, depth).

In this case study, the sources extend above the sea level to model the earthquakes within the volcanic edifice, and also the faults intersect the topographic surface.

These sources are combined together to form alternative seismic source models. Three source model branching levels are defined, in order of increasing complexity, to represent the epistemic uncertainties (Fig. 2).

- Source Model Level 1 is composed of area sources only. Four zones of uniform seismicity are parameterized by Gutenberg-Richter (GR) FMDs calibrated on the bestquality instrumental catalogue (see Sect. 4.1 in Part 1) during an interseismic period that is considered representative of the long-term seismic behavior observed since the 19th century. Seismicity rates are extrapolated until the maximum magnitude observed in the historical period $\left(M_{\max }=5.2\right)$, and effective depths are estimated by the analyses of strain release profiles. The values of parameters entered in both the OpenQuake engine and CRISIS are given in Table 1.

- Source Model Level 2 combines major earthquakes $(M>4.5)$ that are assigned to faults only, with background seismicity that is assigned to area sources as in Level 1 (modeled up to $M_{\max }=4.5$ ). The FMDs of faults are Gaussian distributions peaked to the characteristic earthquake models; rates are branched, based on the historical observations only, or constrained by geometrical and geological-kinematic considerations on fault size and slip rate (observed and calculated mean recurrence time $T_{\text {mean }}$ and maximum magnitude $M_{\max }$ in Table 2; see Pace et al., 2016, for the method; Part 1 for results obtained at Mt. Etna). In Table 2 we summarize the input data and the results in terms of occurrence probabilities of the characteristic earthquake, following a memory-less process (Poisson) or introducing the time dependency of the last event by a Brownian passage time (BPT) model for both the branches (historical and geological-kinematic). Note that the Pernicana fault (PF) is always modeled as GR, not having historical observations supporting the choice of a characteristic earthquake model.

- Source Model Level 3 again assigns the major seismicity to faults, as in Level 2, but background seismicity is modeled by distributed seismicity using scattered point sources (in 3-D) with spatially variable GR rates up to $M_{\max }=4.5$. Since the hypocenters locations determined by a 3-D velocity model take into account the nonuniform crustal properties beneath the volcanic edifice, we prefer this model as it is essentially data-driven and less affected by subjective choices about zonation; we acknowledge that the picture of fragile deformation depicted by the recent low-magnitude seismicity represents the best available context currently. 


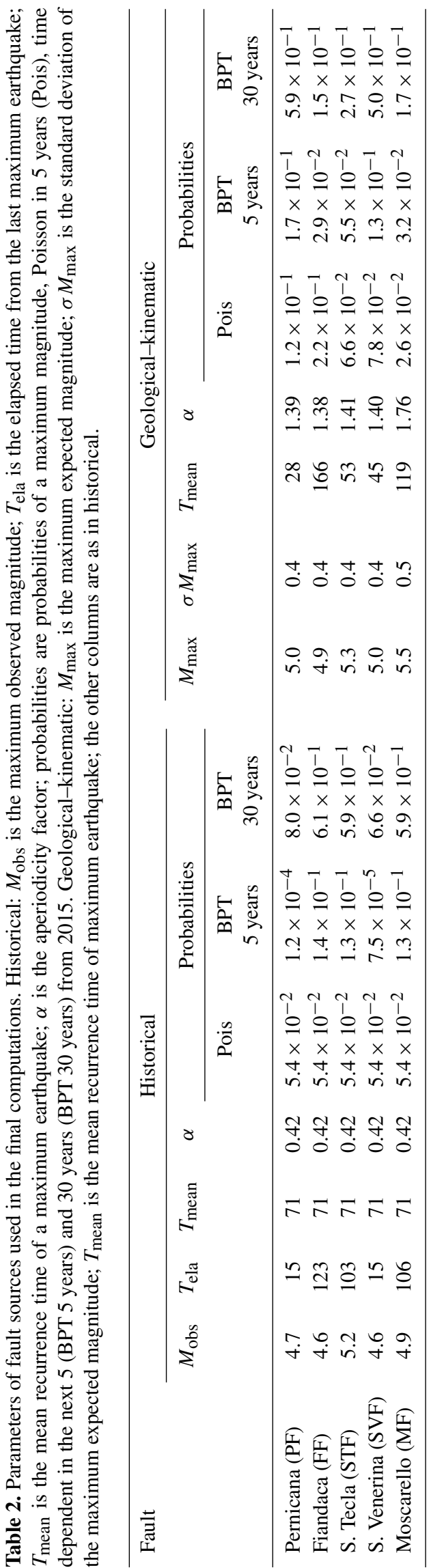

\section{GMPE at Mt. Etna}

A key component of any seismic hazard assessment is the propagation of seismic energy from the source to the receiver, accounted for in a heuristic way by GMPEs, as the details of seismic wave propagation are usually unknown. Volcanic areas often exhibit peculiar characteristics expressed by high attenuation of seismic energy, especially for shallow earthquakes.

Concerning the geological conditions, the Mt. Etna volcanic edifice overlies a thick sedimentary substratum with strong lateral heterogeneities (see, e.g., Branca et al., 2011; De Gori and Chiarabba, 2005). The foci of the shallow events (focal depth less than $5 \mathrm{~km}$ ) fall into a depth range of the abovementioned sedimentary substratum; this affects both the seismic scaling laws (relationship of released seismic energy and size of the source) and the wave propagation phenomena (Patanè et al., 1994; Giampiccolo et al., 2007; see Langer et al., 2016, for a more detailed discussion). Differences between shallow and deep events (focal depth greater than $5 \mathrm{~km}$ ) at Mt. Etna can be clearly identified just looking at the waveforms. For similar magnitude and distance, the shallow events have more low-frequency content than the deeper ones, where conversely the high frequencies prevail (Tusa and Langer, 2016). The distinctiveness of the shallow events makes the application of common ground-motion prediction equations used for tectonic areas questionable and inappropriate.

For the purposes of DPC-INGV V3 project, we derived a local GMPE for the Mt. Etna region, focusing on the shallow events and using the high-quality data collected by the numerous seismic broadband stations that have been operating in eastern Sicily since 2006. We referred to the same sample of data as Tusa and Langer (2016, hereafter TL16), the original GMPE developed for this project, but this time we considered a different distance metric (hypocentral distance instead of epicentral distance as required to incorporate topography into the calculation; see Sect. 4). The dataset consists of a set of 1200 three-component recordings acquired during 38 events in the magnitude range $3.0 \leq M_{\mathrm{L}} \leq 4.3$ with hypocentral distances between 0.5 and $100 \mathrm{~km}$. Moreover, $95 \%$ of the hypocenters are shallower than $2.5 \mathrm{~km}$ (more than $85 \%$ of events have focal depth error equal or less than $0.5 \mathrm{~km}$ ). Note that for our study area, recent investigations suggest that $M_{\mathrm{L}}$ matches $M_{\mathrm{W}}$ values quite well (Saraò et al., 2016). For an extensive description of data processing and the statistical characteristics of the data set, for example, in terms of magnitude, number of data-recording site classes and distance-magnitude distributions, we direct the readers to TL16. In order to compare our data to those recorded in other regions of Italy (in particular the Italian equation by Bindi et al., 2011, hereinafter ITA10), our empirical GMPE follows the simplified version of the formulation proposed by Boore and Atkinson (2008): 
Table 3. Coefficients of Eq. (1) for the prediction of horizontal peak ground acceleration (gal) for the GMPE in this study. Magnitude is defined as $M_{\mathrm{L}}$. CI95 indicates the confidence intervals at $95 \%$ confidence level. In this table, $R^{2}$ is the determination coefficient. $\sigma_{\text {eve }}$ and $\sigma_{\text {sta }}$ are inter-event and inter-station terms of the errors, respectively. $\mathrm{BS}_{\text {mean }}$ and $\mathrm{BS} \sigma$ are the mean value and the standard deviation of each coefficient, respectively, estimated by applying the bootstrap technique.

\begin{tabular}{lrrrrrrrrrrrrr}
\hline & $a$ & $b_{1}$ & $b_{2}$ & $c_{1}$ & $c_{2}$ & $h$ & $c_{3}$ & $e_{\mathrm{B}}$ & $e_{\mathrm{D}}$ & $R^{2}$ & $\sigma_{\text {eve }}$ & $\sigma_{\text {sta }}$ & $\sigma_{\mathrm{T}}$ \\
\hline & 0.329 & 0.105 & 0.076 & -2.111 & 0.039 & 1.553 & 0.006 & 0.450 & 0.457 & 0.853 & 0.228 & 0.222 & 0.394 \\
CI95 & -1.993 & -1.136 & -0.097 & -2.376 & -0.125 & 0.084 & 0.003 & 0.337 & 0.309 & & & \\
& 2.651 & 1.346 & 0.248 & -1.847 & 0.204 & 3.190 & 0.010 & 0.562 & 0.604 & & & \\
BS & 0.381 & 0.073 & 0.080 & -2.106 & 0.040 & 1.174 & 0.006 & 0.455 & 0.463 & & & \\
BS $\sigma$ & 1.039 & 0.554 & 0.078 & 0.140 & 0.078 & 2.780 & 0.002 & 0.076 & 0.084 & & & \\
\hline
\end{tabular}

$$
\begin{aligned}
\log (Y)= & a+b_{1} M+b_{2} M^{2}+\left[c_{1}+c_{2}\left(M-M_{\mathrm{ref}}\right)\right] \\
& \log \left(\sqrt{R^{2}+h^{2}} / R_{\mathrm{ref}}\right)+c_{3}\left(\sqrt{R^{2}+h^{2}}-R_{\mathrm{ref}}\right) \\
& +e_{i} S_{i}+\sigma_{\mathrm{T}},
\end{aligned}
$$

where $M_{\text {ref }}$ is a reference magnitude for magnitude dependence of geometric spreading (here fixed to the mode value of the dataset, equal to 3.6), $R$ is the hypocentral distance in kilometers, $R_{\text {ref }}$ is reference distance at which the near source predictions are pegged (here fixed to a value of $1 \mathrm{~km}$ ) and $h$ is an additional parameter, referred to as "pseudodepth", incorporating all the factors that tend to limit or reduce motion near the source (Joyner and Boore, 1981). The multiplier of the logarithmic distance term accounts for the magnitude-dependent ground-motion decay and controls the saturation of high-frequency ground motions at short distances. $S_{i}$ indicates the soil conditions, with $i$ standing for the soil classes A-D defined in the EC8 building code. The $S_{i}$ variables of Boolean type are set to unity if the corresponding soil class is met at a site, whereas the $S_{i}$ for all other classes is zero. Finally, $\sigma_{\mathrm{T}}$ represents the total standard deviation, which is the uncertainty in $\log (Y)$ (logarithm is with base 10). The basic difference with TL16 is the distance metric, measured with respect to the hypocenter instead of the epicenter. This change allows accounting for the elevation of the seismic stations, which may vary in the range of about $2.5 \mathrm{~km}$, a relevant difference, in particular for areas close to the epicenter.

The coefficients of our model, including the pseudodepth $h$ as well, were estimated applying the classical nonlinear least-squares Marquardt-Levenberg algorithm as implemented in MATLAB. The coefficients of the model are computed by using an iterative least-squares estimation, with specified initial values. In particular, we tested different starting models in order to evaluate their effects on the solution, and at the same time, to select those values towards which the several inversions converged. The equations are derived from the regression analyses for horizontal peak ground acceleration (PGA) and $5 \%$ damped spectral acceleration (SA) at several periods from 0.1 to $10 \mathrm{~s}$. The regression coefficients and their 95\% confidence intervals for PGAs are reported in
Table 3 (for SAs see the Supplement). The value of coefficient $c_{3}$, which stands for inelastic attenuation, is very close to zero and could be potentially omitted from the functional form in Eq. (1). It has a minimal influence on the dependent variable values estimated through the obtained regression model. The standard deviation obtained by bootstrap analysis is given too. The bootstrap bypasses problems in estimating uncertainties of model parameters obtained in nonlinear inversion, which is based on the Jacobian matrix and has the advantage of being applicable without a priori knowledge of the distribution of the underlying parent population. Compared to standard methods, the bootstrap yields a more robust and conservative estimation of parameter uncertainties. Here, in order to assess the stability of estimated regression coefficients, we resampled our data set 1000 times and applied the same regression models as before. Each application gives a different set of regression coefficients and we calculate the statistics over our 1000 sets of coefficients.

The total standard deviation, $\sigma_{\mathrm{T}}$, can be split into two terms:

$\sigma_{\mathrm{T}}=\sqrt{\sigma_{\mathrm{eve}}^{2}+\sigma_{\text {intraeve }}^{2}}$,

where $\sigma_{\text {eve }}$ and $\sigma_{\text {intraeve }}$ are the inter-event and intra-event error components, respectively, representing the error variability for different stations recording the same event and the error variability for different earthquakes recorded by the same station. Similarly, if the variability among recording sites is taken into account, the total standard deviation of $\log (Y)$ in Eq. (1) is given by

$\sigma_{\mathrm{T}}=\sqrt{\sigma_{\text {sta }}^{2}+\sigma_{\text {intrasta }}^{2}}$,

where $\sigma_{\text {sta }}$ and $\sigma_{\text {intrasta }}$ represent the inter-station and intrastation component of the variance. We estimated the intergroup (inter-event and inter-station) and the intra-group (intra-event and intra-station) variance - understood here in terms of mean square errors - for each attenuation model, by applying the "analysis of variance" test. We observe that the horizontal PGA has similar $\sigma_{\text {eve }}$ and $\sigma_{\text {sta }}$ values, whilst the spectral acceleration shows, in general, higher inter-station variability than the inter-event component, suggesting that 

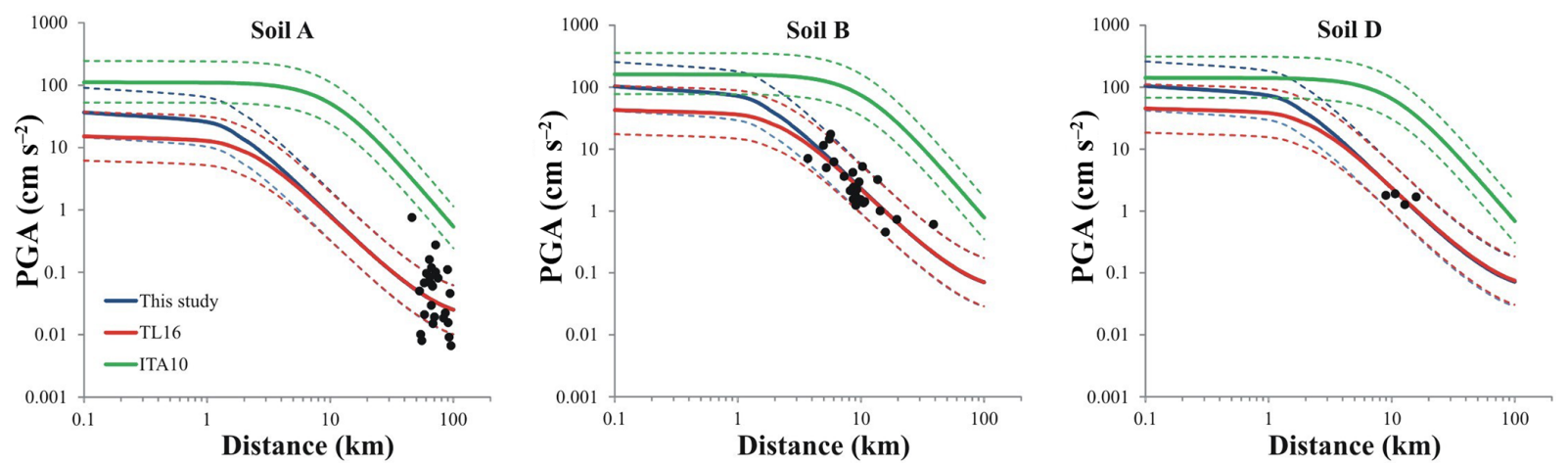

Figure 3. Predicted mean attenuation curves for a $M_{\mathrm{L}}=4$ earthquake by the empirical law estimated in this study: ETNAhy, (continuous blue lines), TL16 (continuous red lines) and ITA10 (continuous green line). The dashed lines represent the standard deviation of the mean. The black circles refer to the observations of our dataset with $3.9 \leq M_{\mathrm{L}} \leq 4.1$; the three frames represent different soil types according to the EC8 Building code.

the local site effects are the main source of ground-motion variability for our data.

In Fig. 3 we compare the predictions of horizontal PGA obtained in this study (coefficients reported in Table 3) with those derived by TL16 for shallow seismic activity at Mt. Etna and by ITA10 for the whole Italian national territory. Differences between the epicentral (TL16) and hypocentral versions of the GMPE (red and blue curves, respectively) are most evident for source-to-site distances $<5 \mathrm{~km}$, where the hypocentral version of the GMPE predicts higher accelerations. ITA10 (green curves) shows evident differences related to the flat part of the attenuation curves at short distances that goes from 0 to $10 \mathrm{~km}$ and more. The extension of this plateau depends critically on the $h$ parameter, and focal depths in ITA10 are larger than the one selected for Mt. Etna, thus leading to a higher $h$ coefficient. Note that ITA10 is based on 793 records from 99 events and 150 stations, collected on the whole Italian territory; our data set offers at least the same or even a better statistical stability, from both the total number of records (1200) and coverage (records per event, records per station and homogeneity from a seismotectonic point of view). From a practical point of view, the use of ITA10 strongly overestimates the PGA for shallow earthquakes at Mt. Etna as it predicts values which differ by a factor of about 3 near the source (distances $<2$ $3 \mathrm{~km}$ ) and much higher values (1-2 order of magnitude) at distances of $5-50 \mathrm{~km}$. A quite different picture is obtained when spectral accelerations are taken into account, for example at $T>0.5 \mathrm{~s}$, where ITA10 shows an underestimation of ground shaking (see Fig. S1 in the Supplement). This is due to the fact the spectra of shallow events at Mt. Etna are richer in low frequencies than the earthquakes normally considered in GMPE, which are located at depth into the crystalline basement.

The GMPE equations obtained by this study have been implemented in the software packages used for our analyses and will be referred to hereinafter as the ETNAhy GMPE model.
In CRISIS, the ETNAhy GMPE has been used by means of precompiled attenuation tables: an example for PGA and $\mathrm{SA}$ at $0.2,0.4$ and $1.0 \mathrm{~s}$ for soil type A is given as Supplement. Note that the magnitude range of applicability (stated in the data sample at 3.0-4.3 and slightly extended in this precompiled table up to values 2.6-5.3) covers values usually not represented by standard GMPEs. In the OpenQuake engine, ETNAhy has been added to the library of GMPEs (https://github.com/gem), which also includes TL16, the version for $R_{\text {epi }}$. Verification of the implementation was performed by testing the expected mean and standard deviation output of the GMPE against a table of expected values provided by the authors for different combinations of input variables (e.g., magnitude, distance, $V_{\mathrm{s} 30}$ ).

\section{Accounting for topography}

Another implementation introduced in this study concerns the capability of taking into account the surface topography (elevation) in PSHA calculation. Typically in PSHA, the sites of the hazard computation are defined in terms of their geographic coordinates on a planar surface representative of the sea level. This implies that the elevations of the sites are assumed to be zero, and the source-to-site distances in the PSHA calculation are computed accordingly. Usually this is an appropriate approximation because the actual elevations of the sites are small compared to the depths of the sources. However, in the case of Mt. Etna, this approximation cannot be made. Here, the earthquakes are shallow (mostly within the upper $5 \mathrm{~km}$, and some even above the sea level inside the volcanic edifice) and the elevation of the volcano increases, sharply moving from the coast to the central craters, which are more than $3 \mathrm{~km}$ a.s.l.

A cross section of Mt. Etna is shown in Fig. 4, illustrating how the surface topography effects source-to-site distances. In this example, the distance $R_{\text {hypo }}$ - as used by the GMPE 


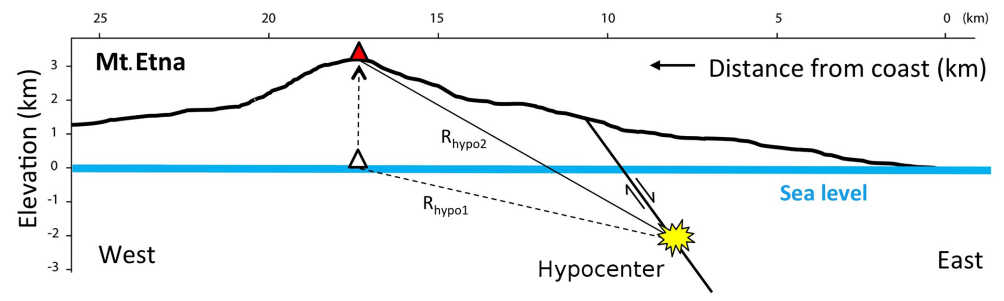

Figure 4. A topographic profile of Mt. Etna shown to scale, extending from the western side of the volcano to the eastern coast (Ionian Sea). Using a hypothetical fault, it can be demonstrated how the source-to-site distance increases $\left(R_{\text {hypo } 2}>R_{\text {hypo1 }}\right)$ if the site is defined on the topographic surface (red triangle) compared to the sea level (clear triangle).
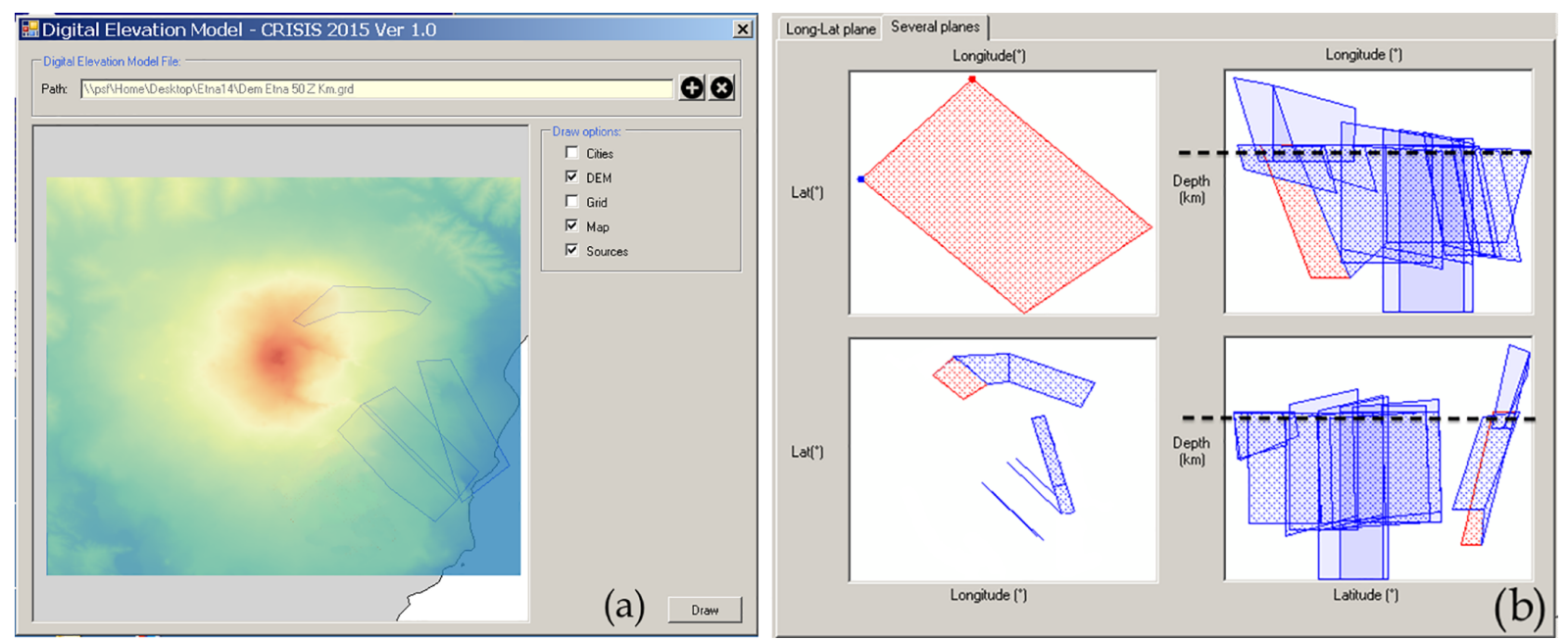

Figure 5. Snapshots of topography and sources in CRISIS. (a) DEM at Mt. Etna with area sources. (b) Preliminary release of fault sources in a 3-D view: the panel in the upper left shows a red fault plane which is projected with other fault sources in lower left; the panels on the right are classical cross sections along longitude (upper) and latitude (lower). Note the vertexes above the sea level, marked by black dashed lines in the cross sections.

in this study - increases when the topographic surface is included because the site elevation is increased. Note that for some source-to-site combinations, a straight path from the source to the site passes in the air above the free surface (for example if the site is at the very top of Mt. Etna and a shallow source is located a few kilometers away from the base) and therefore cannot be realistically followed by seismic waves. However, we find that the curvature of the topography is not pronounced enough (i.e., the slope of the topography changes gradually at the scale of the volcano) to cause a significant difference between a liner source-to-site path and a path that follows the free surface topography, and therefore we accept the approximation of a linear source-to-site path. Note that the influence of the topographic surface we describe here is purely a geometrical one and should not be confused with topographic site effects, where seismic waves are amplified in the vicinity of summits (see, for example, Imperatori and Mai, 2015, and references therein); improvements in ruptureto-site distance metrics related to topographic effects are beyond the scope of this paper.
In order to correctly compute the source-to-site distances in the hazard calculation, we implemented the possibility to model a 3-D topographic surface into both software packages. In CRISIS, this functionality has been added since the release V1.0 of 2015, by means of a specific layer that represents the topography of the study area. A digital elevation model, given in a gridded data file, can be uploaded and the sites elevations are automatically computed on this surface (Fig. 5). The capability in the OpenQuake engine has been available since early 2017 (V2.3.0) and enables the user to specify the sites of the hazard calculation in terms of longitude, latitude and depth coordinates with respect to the sea level, for example in the form of a csv file. In both software packages, sources may also be defined above the sea level, using the convention of negative values for indicating elevations above sea level.

This new functionality can be extended to other regions, although it is most appropriate in cases when the inclusion of topography is relevant to hazard (i.e., shallow sources with respect to the topographic elevation; see for example Peruzza et al., 2016), and source locations are well constrained with 

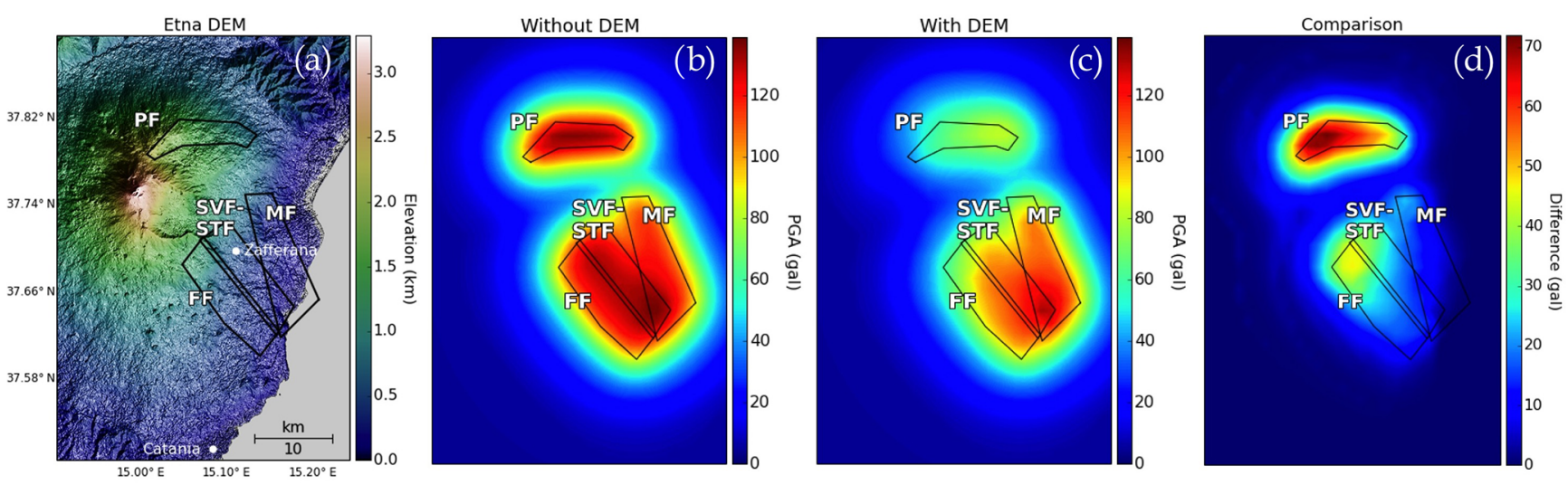

Figure 6. A hypothetical example showing the sensitivity of the hazard results to topography considering area sources and using the OpenQuake engine. The source geometries have assigned the same FMD and a depth of $2.5 \mathrm{~km}$. (a) Etna DEM, (b) hazard without DEM (sites at sea level), (c) hazard with DEM (sites on topographic surface) and (d) residuals (given by b minus c values).

respect to the sea level, as is the case at Mt. Etna. In theory, site locations may also represent surfaces that are not exposed (e.g., the sea bottom, or bedrock lying below alluvial deposits), thus opening new potentialities for integrating sitespecific response into hazard computation. As incremented capabilities may also introduce new problems for Mt. Etna analyses (i.e., how to account correctly for bedrock response if we are not in free-field conditions), we will accept the simplification that the topographic surface represents reference sites on bedrock.

We performed sensitivity tests at Mt. Etna to compare the software performances and to show the contribution of topography to the hazard. CRISIS and the OpenQuake engine behave the same in the simplest source formulation, e.g., area and point sources, and very similarly when complex faults are treated. To demonstrate the influence of topography, we use the same area sources as this hazard assessment but assign all of them the same FMD and a depth of $2.5 \mathrm{~km}$, with the seismogenic layer extending from 0 to $5 \mathrm{~km}$ (Fig. 6). We find that including topography causes an increase in sourceto-site distance and therefore a decrease in hazard that locally reaches about $50 \%$ of the values compared to the model that does not include topography. This effect is most pronounced in the regions of maximum elevation, notably the sources closest to the central craters (i.e., PF, the Pernicana area source). A similar effect is obtained by modeling fault sources too, but less pronounced as all the faults outcrop.

\section{Accounting for site-specific response}

We investigated the site-specific seismic response in the densely populated eastern flank of Mt. Etna by adopting the commonly used horizontal to vertical spectral ratio techniques that evaluate the site response properties using both earthquake (HVSR) and ambient noise (HVNR) as input signals (Nogoshi and Igarashi, 1971; Nakamura, 1989; Lermo and Chavez-Garcia, 1993). Although these methodologies are commonly applied in areas showing strong impedance contrast or minor lateral heterogeneities, they have been widely applied with valuable results in volcanic areas characterized by a complex geologic setting (e.g., Lombardo et al., 2006; Panzera et al., 2013, 2016, 2017; Rahpeyma et al., 2016).

The HVSRs were performed by selecting 30 local events that occurred in the volcanic area with $M_{\mathrm{L}}>2.5$; records were extracted from the INGV Osservatorio Etneo database, while location and magnitude were taken from the bulletins (Gruppo Analisi Dati Sismici, 2017). Recorded earthquakes were baseline corrected, with the purpose of removing spurious offsets, and bandpass filtered in the range $0.08-20 \mathrm{~Hz}$, with a fourth-order causal Butterworth filter. The analysis was performed by using $20 \mathrm{~s}$ time windows, starting from the S-wave onset, including part of the coda, and using a $5 \%$ cosine-tapered window. Fourier spectra were smoothed using a Konno-Ohmachi filter (Konno and Ohmachi, 1998) and the selected time window was compared with the pre-event noise in order to select good-quality data based on the signalto-noise $(S / N)$ ratio. For each recording, only those signals with $S / N \geq 3$ were considered for analysis. The spectral ratios were evaluated at each station for the selected events and a geometric mean of all spectral ratios were computed to obtain the mean HVSR curve and the corresponding standard deviation. The obtained HVSRs were grouped into four "spectral classes" by considering the frequency at which the dominant HVSR peak occurs, using the following criteria:

- ET-1 class: flat spectral ratios showing amplitude values not exceeding two units (including standard deviation);

- ET-2 class: HVSR having fundamental period $T \leq 0.2 \mathrm{~s}$ with amplitude exceeding two units;

- ET-3 class: HVSR with fundamental period $0.2<T \leq 1.0 \mathrm{~s}$ with amplitude exceeding two units; 

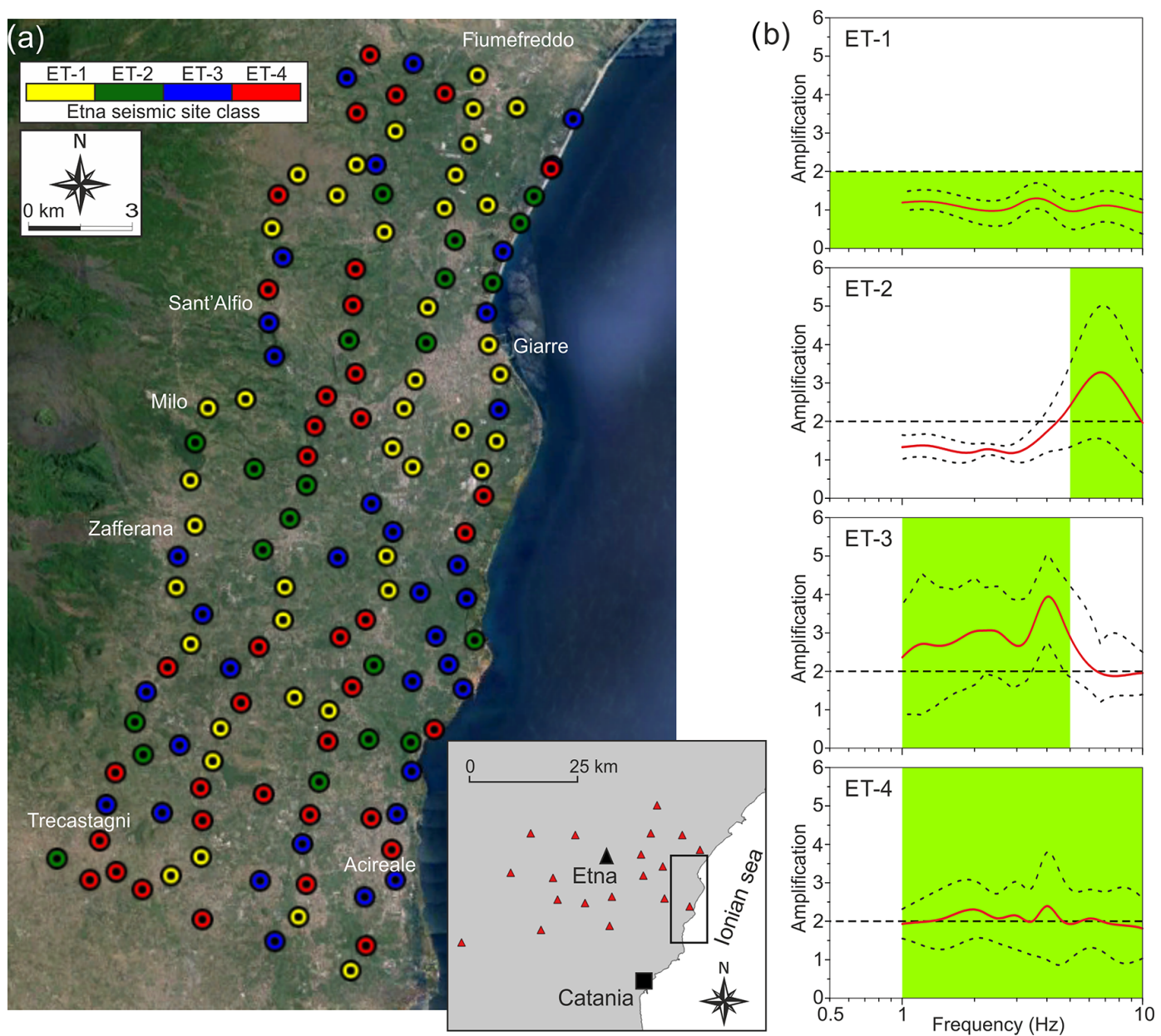

Figure 7. Site amplification at Mt. Etna. (a) Sites investigated by HVNR measurements, where different colors point out the assigned "spectral class" given in the legend. In the inset map, location of the investigated area (black rectangle) and seismic stations (red triangles) used for the evaluation of the site amplification functions. (b) Site amplification functions (mean value in red, standard deviation with dashed black curves; see also Longo, 2017) obtained by grouping the HVSR inversions of seismic stations.

- ET-4 class: HVSR showing broadband amplitude exceeding two units.

Besides, each experimental HVSR was inverted through ModelHVSR MATLAB routines (Herak, 2008) in order to compute theoretical HVSRs in homogeneous and isotropic layers. For the 19 considered seismic stations at Mt. Etna (stations locations are shown in the inset map of Fig. 7a), the stratigraphic sequence and local velocity model were made by integrating literature information and geological observations (Azzaro et al., 2010; Branca et al., 2011; Branca and Ferrara, 2013; Panzera et al., 2011, 2015; Priolo, 1999). The soil models consist of a number of viscoelastic layers, stacked over a half-space, each of them being defined by the thickness $(h)$, the velocity of the body waves $\left(V_{\mathrm{p}}\right.$ and $\left.V_{\mathrm{s}}\right)$, the density ( $\rho$ ) and the $Q$ factor, which controls the inelastic properties. The code assumes that incoming waves are traveling vertically and considers that horizontal and vertical motions at the bedrock have no amplification. The HVSR at the surface is then obtained as the ratio between the theoretical transfer functions of S and P waves (Herak, 2008). The obtained HVSR output models were then used as input for the amplification function (AF) for 14 seismic stations. Five stations, showing lack of convergence between the experimental and theoretical model, were removed. The AFs were computed through frequency-domain calculations, using the program SiteAmp by Boore (2003) that converts a velocity and density model into site amplifications. In particular, the Fortran code calculates the Thomson-Haskell plane SH-wave transfer function for horizontally stratified constant velocity layers at a specific incidence angle within a uniform velocity half-space. The input parameters are the $V_{\mathrm{s}}$, the density $(\rho)$ and $Q$. The half-space is set at the deepest measured layer and the solution is exactly equivalent to the solution computed by the equivalent linear site response program SHAKE for linear modulus reduction and damping curves (Schnabel et al., 1972). The code computes the amplifications either at 

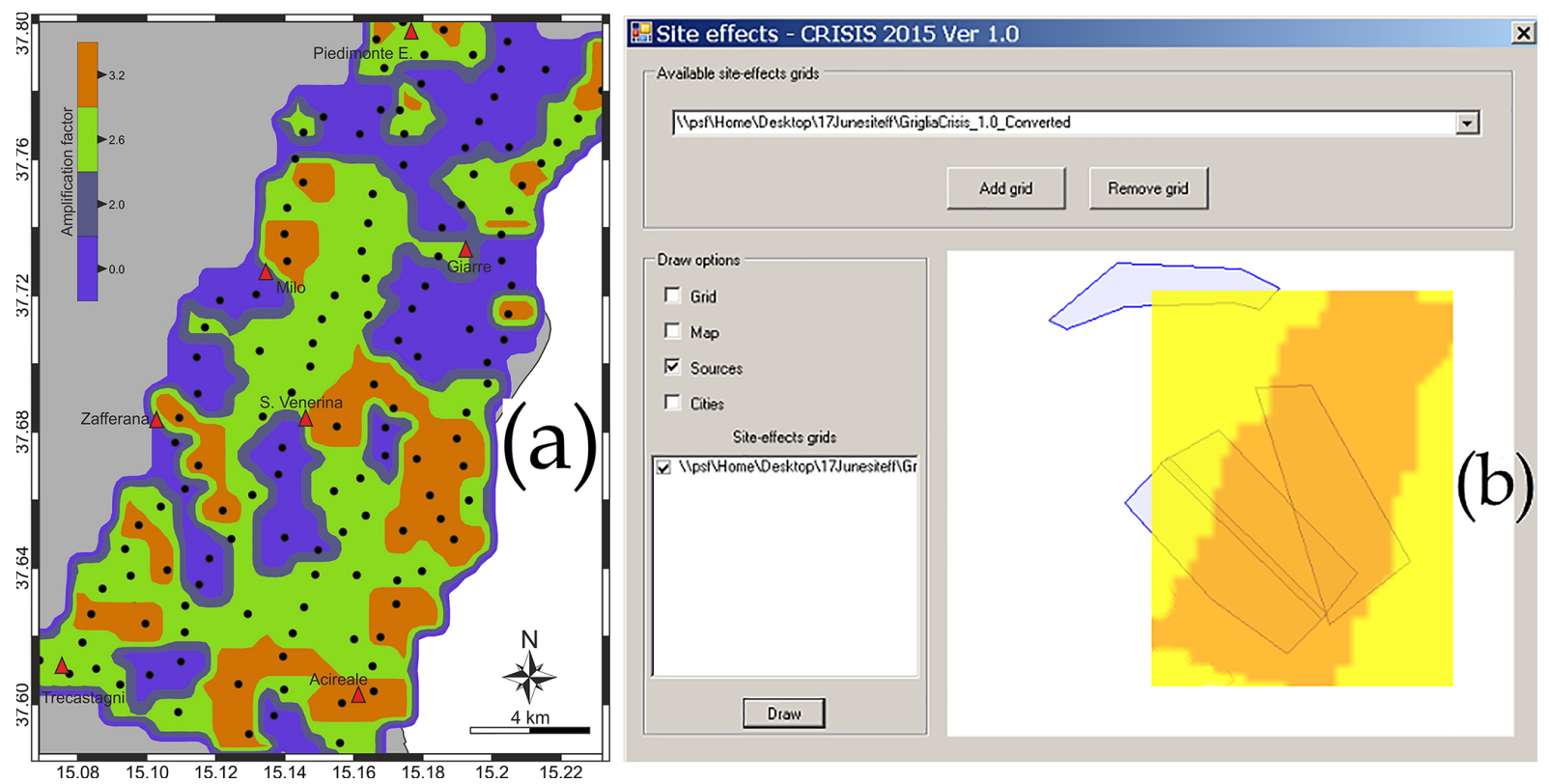

Figure 8. Simplified site-specific response along Mt. Etna's southeastern flank. (a) Amplification factors at SA 0.2 s, obtained by interpolating the measured sites using the nearest neighbor algorithm. (b) Amplification factors as implemented in CRISIS; orange stripe represents the area where amplification factors enter in hazard computations.

specified frequencies or at frequencies corresponding to the "breakpoints" in the velocity model.

This procedure allowed us to assign an $\mathrm{AF}$ to each of the four HVSR classes previously identified by averaging the AFs of all the stations included in the class (Fig. 7b).

The European project Site Effects Assessment Using Ambient Excitations (SESAME, 2004) found that the ambient vibration method is a reliable alternative approach to using earthquake records especially for estimating the fundamental frequencies of a site. For this reason we performed a comparison between experimental HVSRs and HVNRs obtained at the seismic stations located around the volcano. The good matching obtained encouraged us to consider the ambient noise signal as a valid seismic input to be used to define the site fundamental frequency. We therefore proceeded to obtain the fundamental period classification in a wide sector of the lower eastern flank of Mt. Etna that includes $14 \mathrm{mu}-$ nicipalities and many villages and rural settlements (Fig. 7a, colored dots). As highlighted in Part 1, this area is the most affected by strong shaking due to the seismogenic activity of the Timpe faults, and hence it is an appropriate choice for investigating the role of site-specific seismic responses. The fast and inexpensive HVNR technique has been performed by 130 georeferenced noise measurements recorded using a three-component velocimeter on a grid of sites quite homogeneously spaced at about $1 \mathrm{~km} \times 2 \mathrm{~km}$ distance. All the HVNRs in the present study were performed using time series of $30 \mathrm{~min}$ length, with a sampling rate of $128 \mathrm{~Hz}$. Signals were processed by considering time windows of $30 \mathrm{~s}$, selecting the most stationary part, excluding transients asso- ciated with very close sources. In this way, the Fourier spectra were calculated in the frequency range of $0.1-30.0 \mathrm{~Hz}$ and smoothed using a proportional $20 \%$ triangular window. Following the criteria suggested by SESAME, only the spectral ratio peaks with amplitude greater than two units, in the frequency range $0.5-10 \mathrm{~Hz}$, were considered significant. The obtained HVNRs were manually classified and grouped into the four classes of predominant period previously identified (colored dots in Fig. 7a).

A preliminary predominant-period site classification in the Mt. Etna's eastern flank is finally attempted to overcome the one based on average shear wave velocity classification of the upper $30 \mathrm{~m}\left(V_{\mathrm{s} 30}\right)$. We mapped in the format required by CRISIS the coefficients to be used in site-specific seismic hazard map, after interpolation of amplification factors at some spectral ordinates done by nearest neighbor algorithm (Fig. 8). According to Barani and Spallarossa (2016), this soil hazard method can be considered a hybrid probabilisticdeterministic method, and it may be useful to provide a first representation of seismic soil hazard at a large scale.

\section{Results}

We computed the hazard at Mt. Etna for the three source branching levels (depicted in Fig. 2), using the ETNAhy GMPE and the MSR derived specifically for this volcanic region as described in Sect. 3 and Part 1, respectively. Computations are for short-to-mid-exposure periods $(10 \%$ exceedance probability in 5 and 30 years). Seismic hazard maps 


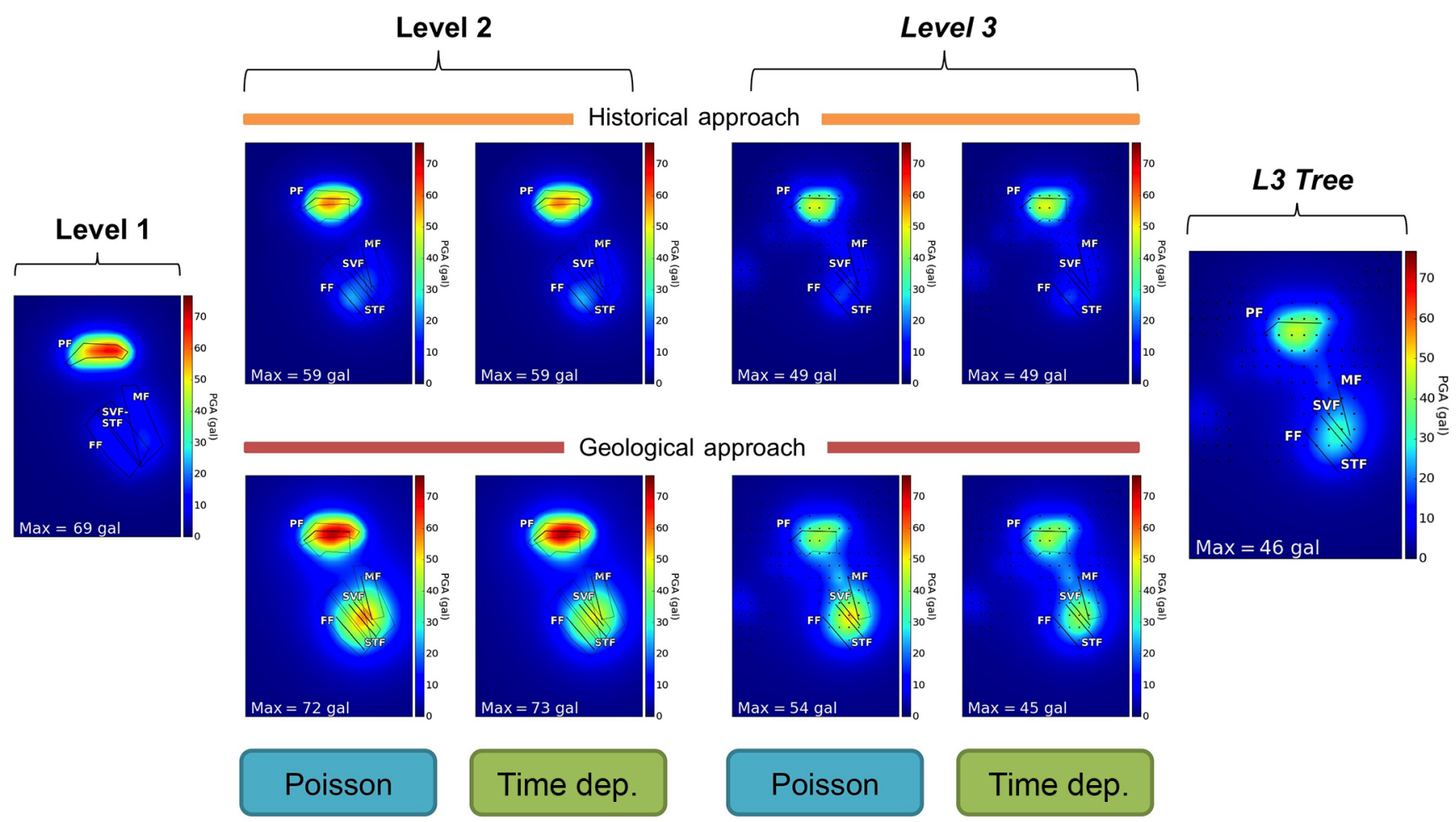

Figure 9. Hazard results for a $10 \%$ exceedance probability in 5 years in terms of PGA, when $V_{\mathrm{s} 30}=800 \mathrm{~m} \mathrm{~s}^{-1}$. Thickest lines indicate fault traces.

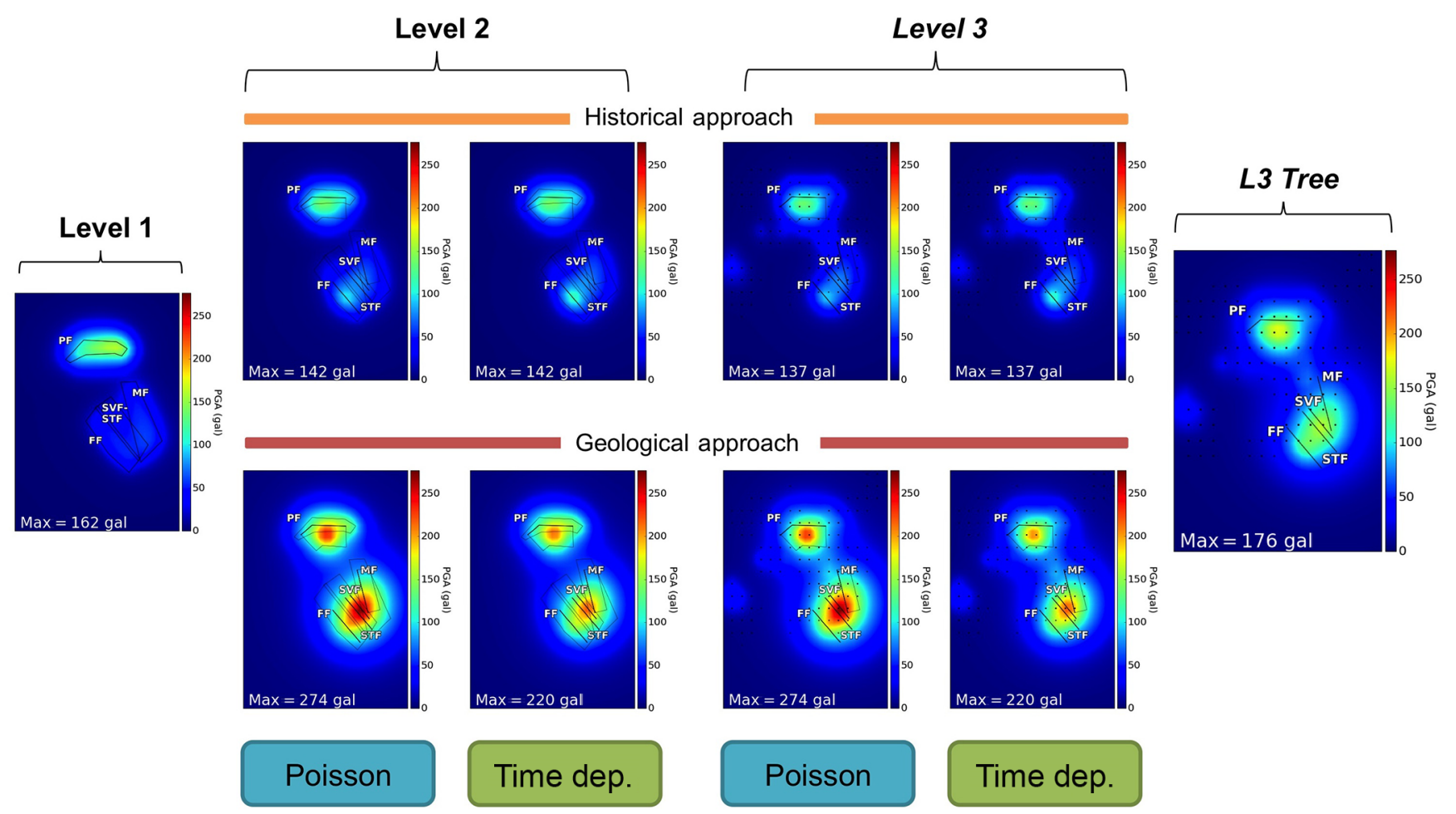

Figure 10. Hazard results for a $10 \%$ exceedance probability in 30 years in terms of PGA, when $V_{\mathrm{s} 30}=800 \mathrm{~m} \mathrm{~s}^{-1}$. Thickest lines indicate fault traces. 
refer to rock conditions, where $V_{\mathrm{s} 30}=800 \mathrm{~m} \mathrm{~s}^{-1}$ (Figs. 911 , and exploratory site-specific results are also shown (Fig. 12).

The results obtained with the OpenQuake engine in terms of PGA are shown in Figs. 9 and 10. For a 5-year exposure period and a $10 \%$ exceedance probability (Fig. 9), the maximum PGA (73 gal) is seen in Level 2, when using seismic rates calculated with the geological-kinematic parameters under the time-dependent assumption (a BPT model is used, where the conditional probability of occurrence is based on the time elapsed since the last characteristic event; see Part 1 and Pace et al., 2016, for details). We find in general that the purely geological approach results in higher hazard compared to the ones obtained by the historical macroseismic earthquake data (historical approach). For a 30-year exposure period (Fig. 10), the maximum PGA (274 gal) is seen in both levels 2 and 3, when using the geologicalkinematic approach and Poisson model. Again, we observe that the geological-kinematic approach gives higher hazard compared to the historical approach (in this case, over 2 times higher), and that hazard is also higher when the occurrence rates on the faults have been derived using the Poisson model compared to the time-dependent model. Within the Timpe fault system, for both exposure periods, the Fiandaca fault (FF) dominates the hazard for the historical approach, while for the geological-kinematic approach the S. Tecla and S. Venerina faults (STF, SVF) dominate the hazard. To give context to these values, the current national hazard map (MPS04, see http://esse1-gis.mi.ingv.it/), which considers regional tectonic events not modeled in this analysis, shows PGA values around $0.20-0.25 \mathrm{~g}$ (196-245 gal) for the region of Mt. Etna, for an exposure period of 50 years. These values fall between the historical and geological-kinematic approaches of our analysis, considering an exposure period of 30 years. We performed a preliminary disaggregation test in terms of magnitude and distance considering only the area sources of Level 1 (time-independent model) and the four area sources from the MPS04 national hazard model closest to Mt. Etna; the results confirm that the hazard in our study area is dominated by the local volcano-tectonic events and not by the larger (M6+) events in the region for return times of 3-5 centuries.

We also used a logic tree in order to combine the results of the different models. The purpose of a logic tree is to account for the epistemic uncertainty, such as the three branching levels used here that represent different modeling approaches, meanwhile avoiding duplication of similar models. For this reason, we chose to neglect levels 1 and 2 in our logic tree weighting, under the assumption that the same information is contained in Level 3, i.e., the 3-D gridded seismicity is a more complex representation of the distributed seismicity in Level 1, and the fault sources are modeled in the same way as in Level 2. For the final logic tree, we therefore weighed the four models in Level 3 (historical Poisson, historical time dependant, geological Poisson, geological time dependant) equally with weights of 0.25 . In the final mean hazard maps, we obtained maximum PGA values of 46 and $176 \mathrm{gal}$, for exposure periods of 5 and 30 years, respectively. For a 5year exposure period (Fig. 9, "L3 Tree" frame), the hazard is highest around the PF, while for a 30-year exposure period (Fig. 10, "L3 Tree" frame), the hazard is similarly high also around STF and SVF.

In some of the hazard maps, the hazard pattern appears concentrated around the middle of the fault sources in a radial pattern. This is most notable around the PF using the geological-kinematic approach for an exposure period of 30 years. This is due to the combination of the following: (1) the fault sources have been assigned Gaussian FMDs centered near the magnitude of the characteristic earthquake (i.e., full fault rupture), and therefore finite ruptures which have areas defined by the Etna MSR (see Part 1) float minimally along strike; and (2) the ETNAhy GMPE is in terms of a point source distance metric $\left(R_{\text {hypo }}\right)$, which means that ground motion is calculated as a function of distance from the center of the rupture (we assume hypocenters are located at the center of the ruptures). The combination of minimal rupture floating and the use of $R_{\text {hypo }}$ in the GMPE results in a hazard pattern that is highest around the centroid of the fault surface, which is consistent with the assumption that faults rupture bilaterally.

The simplest model, Level 1, is also computed for some spectral ordinates (Fig. 11) in addition to PGA values (reported in Figs. 9 and 10). For the spectral ordinates considered, SA $0.2 \mathrm{~s}$ gives the highest hazard, with maximum values of 109 and 241 gal for $10 \%$ exceedance probability on exposure periods of 5 and 30 years, respectively. For all the exposure periods and spectral ordinates calculated, the hazard of Level 1 is dominated by PF, but note the relative increase of values in the southeasternmost area of the Timpe, as the spectral ordinate shifts toward lower frequencies. The results using CRISIS confirm these values and will be used for the site-specific test, given below.

Lastly, the amplification factors obtained by instrumental measures in the eastern flank of Mt. Etna have been used in CRISIS. They give the first seismic hazard site-specific maps based on real response data and clearly illustrate how amplification due to local site conditions can increase the expected ground motion at rock reference sites. Even if these results are preliminary, they can be considered the first example of a new generation of site-specific seismic hazard maps suitable for defining priorities of retrofitting at a local scale. In Fig. 12, site-amplified results at two spectral accelerations $(0.2$ and $1.0 \mathrm{~s})$ for a $10 \%$ probability of exceedance in 5 and 50 years are shown. The obtained values show that the sitespecific conditions are by far the most important elements in driving the hazard, and the variability in ground motion alters the spatial correlations of nearby localities. Further studies will deepen these analyses by checking how we can bridge the gap existing between the probabilistic physically based models (like the study presented here) and the ones obtained 

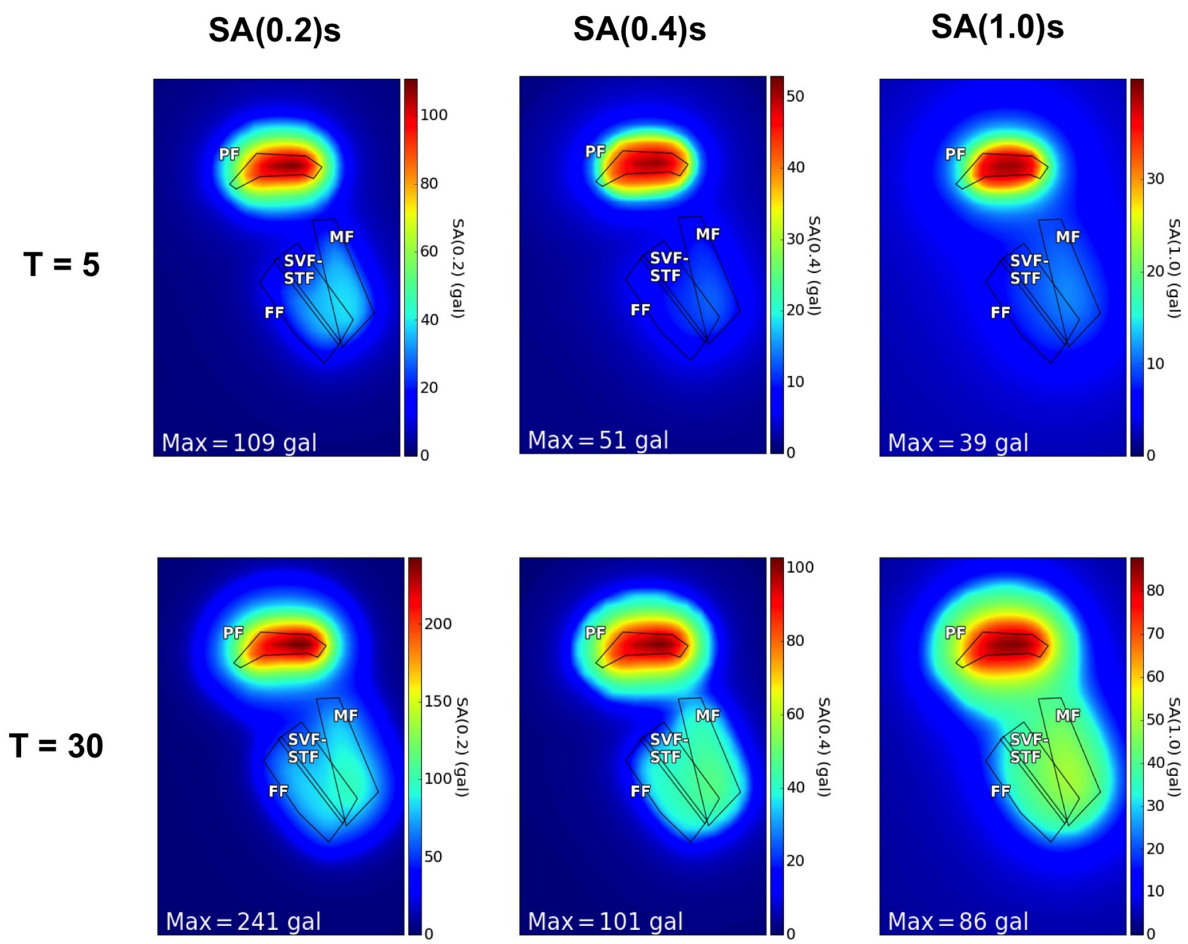

Figure 11. Hazard results of Level 1 at different spectral ordinates for a $10 \%$ exceedance probability in 5 and 30 years, when $V_{\mathrm{s} 30}=800 \mathrm{~m} \mathrm{~s}^{-1}$.

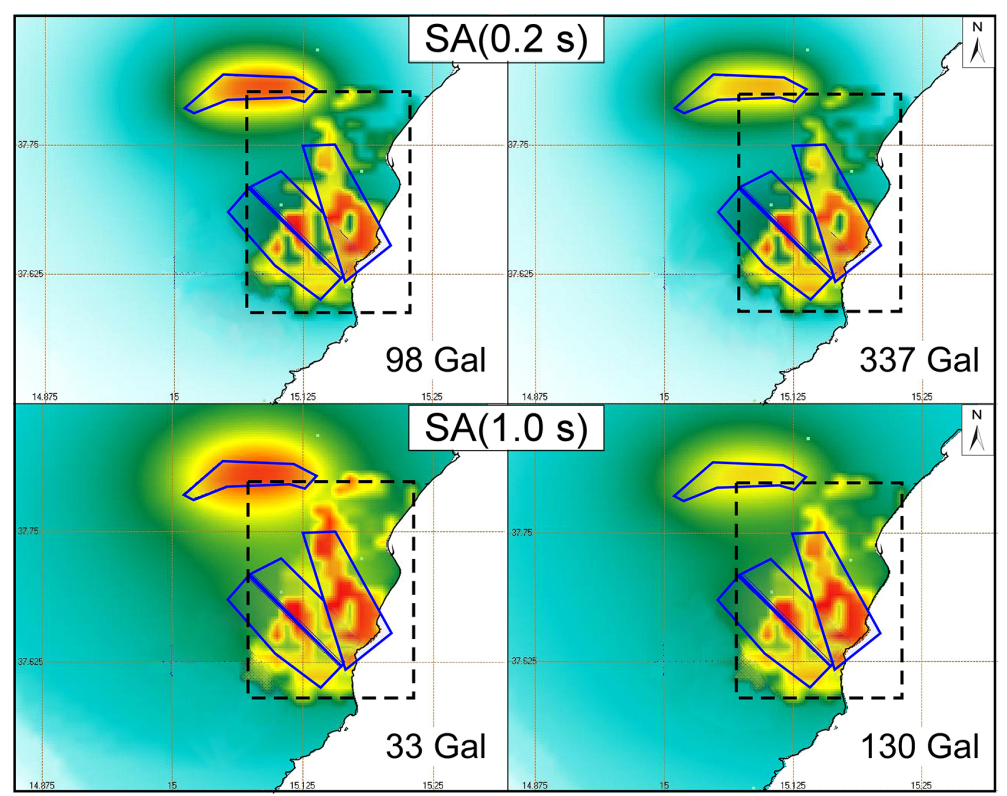

Figure 12. Site-specific hazard results of Level 1 (CRISIS). In the upper panels, the maps of SA $0.2 \mathrm{~s}$ at $10 \%$ exceedance probability in 5 (left panels) and 50 years (right panels) are obtained for $V_{\mathrm{s} 30}=800 \mathrm{~m} \mathrm{~s}^{-1}$ for the whole area; the amplification factors are applied on a stripe on Mt. Etna southeastern flank (dashed black rectangle, see details in Figs. 7 and 8). The lower frames refer to SA 1.0 s.

by means of the observed intensities (Azzaro et al., 2008, 2016). By now, we acknowledge that the two approaches differ mainly in the less-inhabited areas where seismic sources are defined by instrumental methods only; thus the problem of seismic sources definition deals essentially with issues of completeness and epistemic uncertainties.. 


\section{Conclusive remarks}

This work presents the first seismic hazard maps specifically obtained for a volcano, Mt. Etna in Sicily, and the implementations introduced ad hoc in two PSHA software packages (CRISIS, Ordaz et al., 2013; OpenQuake engine, Pagani et al., 2014). Results are given in terms of acceleration (PGA and spectral ordinates at $0.2,0.4$ and $1.0 \mathrm{~s}$ ) for shorter return periods than those normally used in regulation, i.e., for a $10 \%$ exceedance probability in 5 and 30 years (corresponding to return periods of 47 and 284 years, respectively) as they are intended to be a tool for prioritization of risk mitigation actions.

The main novelties introduced in this study are as follows:

- The derivation and the introduction of a new GMPE into the software account for the peculiar propagation properties in this volcanic area: it takes into account hypocentral distance $\left(R_{\text {hypo }}\right)$ and is used jointly with an original magnitude-rupture relationship (see Part 1 companion paper, Azzaro et al., 2017), derived from the Mt. Etna dataset.

- New computational capabilities in PSHA software are implemented by introducing the rough volcano topography, which both softwares benefitted from. Accounting for more realistic source-to-site distances can impact results up to $50 \%$ of the expected values for the shallowest sources in the near field.

- The conceptual composition of seismic sources is handled in a framework of increasing complexity. Mt. Etna sources are depicted through an extensive analysis of geological, historical and instrumental earthquake data, described in detail in Part 1. A basic observation is that a high-quality instrumental monitoring obtained during an interseismic period of 10 years at Mt. Etna is representative of the frequency-magnitude distribution derived from a 2-century-long historical catalogue. This encouraged us to use the non-declustered catalogue for parameterizing the seismic sources, potentially opening the usage of generalized, non-Poissonian models for treating the earthquake generation processes in volcanic areas. Further studies are planned to check the applicability of such assumptions in other contexts.

- The seismic sources have been structured in three independent layers, some of them branching to account for different parameterization (e.g., based on historical or geological constraints, to handle the uncertainty of $M_{\max }$ for a fault source) or different assumptions (e.g., about time dependency, using Poissonian stationary rates, or probability rates conditioned to the time elapsed since the last major event, based on simplified BPT distributions). We believe in this way the epistemic uncertainties are properly accounted for.
The hazard maps computed in our study have higher spatial resolution than the national hazard maps, and those referred to rock conditions (where $V_{\mathrm{s} 30}=800 \mathrm{~m} \mathrm{~s}^{-1}$, i.e., soil type A) indicate significantly higher hazard than the ones used by regulation, even though they only consider shallow volcanotectonic sources and do not account for the regional sources capable of releasing $M>6$ earthquakes like the national hazard maps do. A preliminary modeling of site-specific hazard is also attempted on the Mt. Etna's eastern flank, where extensive fieldwork has been performed for characterizing local amplification factors. They provide a new picture of expected ground motion, about twice the values assigned to reference rock sites, and are spatially uncorrelated.

We hope that these analyses will be deepened and broadened by the extensive microzonation investigations carried out in the frame of the activities promoted and funded by the Italian Department for Civil Protection (e.g., http://www.protezionecivile.gov.it/jcms/it/piano_ nazionale_art_11.wp) and integrated into the regulation framework in order to have realistic and useful groundmotion prediction maps devoted to urban planners and structural designers.

Finally, we hope that components of this work can be useful in the seismic hazard assessment of other volcanic regions.

Code and data availability. The implementation information of the codes CRISIS and OpenQuake is available with the current releases (https://sites.google.com/site/codecrisis2015/home; https:// github.com/gem/oq-engine, last accessed 30 September 2017). Other details of the source models are provided in Azzaro et al. (2017) and can be provided on demand.

\section{The Supplement related to this article is available online at https://doi.org/10.5194/nhess-17-1999-2017- supplement.}

Competing interests. The authors declare that they have no conflict of interest.

Special issue statement. This article is part of the special issue "Linking faults to seismic hazard assessment in Europe". It is not associated with a conference.

Acknowledgements. Many thanks are due to G. Weatherill, to an anonymous reviewer and to the Guest Editor O. Scotti, for fruitful discussions and suggestions about methodological issues. This study has benefited from funding provided by the Italian Presidenza del Consiglio dei Ministri - Dipartimento della Protezione Civile (DPC), in the framework of the 2012-2014 Agreement with Istituto Nazionale di Geofisica e Vulcanologia (INGV), projects V3 "Multi-disciplinary analysis of the relationships between tectonic 
structures and volcanic activity" and S2 "Constraining observations into seismic hazard". This paper does not necessarily represent DPC official opinion and policies.

Edited by: Oona Scotti

Reviewed by: Graeme Weatherill and one anonymous referee

\section{References}

Abe K.: Magnitudes of major volcanic earthquakes of Japan 1901 to 1925, J. Fac. Sci., Hokkaido Univ. Ser. VII, 6, 201-212, 1979. Alparone, S., Maiolino, V., Mostaccio, A., Scaltrito, A., Ursino, A., Barberi, G., D’Amico, S., Di Grazia, G., Giampiccolo, E., Musumeci, C., Scarfì, L., and Zuccarello, L.: Instrumental seismic catalogue of Mt. Etna earthquakes (Sicily, Italy): ten years (2000-2010) of instrumental recordings, Ann. Geophys., 58, S0435, https://doi.org/10.4401/ag-6591, 2015.

Azzaro, R.: Seismicity and active tectonics in the Etna region: constraints for a seismotectonic model, in: Mt. Etna: volcano laboratory, edited by: Bonaccorso, A., Calvari, S., Coltelli, M., Del Negro, C., and Falsaperla, S., American Geophysical Union, Geophys. Monogr., 143, 205-220, 2004.

Azzaro, R. and De Rosa R.: Project V3. Multi-disciplinary analysis of the relationships between tectonic structures and volcanic activity (Etna, Vulcano-Lipari system), Final Report 1 November 2014-30 June 2015, Agreement INGV-DPC 2012-2021, Volcanological programme 2012-2015, Miscellanea INGV, 29, 172 pp., 2016.

Azzaro, R., Barbano, M. S., Moroni, A., Mucciarelli, M., and Stucchi, M.: The seismic history of Catania, J. Seismol., 3, 235-252, 1999.

Azzaro, R., Barbano, M. S., D’Amico, S., Tuvè, T., Albarello, D., and D'Amico, V.: First studies of probabilistic seismic hazard assessment in the volcanic region of Mt. Etna (southern Italy) by means of macroseismic intensities, Bollettino di Geofisica Teorica e Applicata, 49, 77-91, 2008.

Azzaro, R., Carocci, C. F., Maugeri, M., and Torrisi, A.: Microzonazione sismica del versante orientale dell'Etna studi di primo livello, edited by: Le nove Muse, Catania, 181 pp., 2010.

Azzaro, R., D’Amico, S., Peruzza, L., and Tuvè, T.: Earthquakes and faults at Mt. Etna (Southern Italy): problems and perspectives for a time-dependent probabilistic seismic hazard assessment in a volcanic region, Bollettino di Geofisica Teorica e Applicata, 53, 75-88, 2012.

Azzaro, R., D’Amico, S., Peruzza, L., and Tuvè, T.: Probabilistic seismic hazard at Mt. Etna (Italy): the contribution of local fault activity in mid-term assessment, J. Volcanol. Geoth. Res., 251, 158-169, 2013.

Azzaro, R., D'Amico, S., and Tuvè, T.: Seismic hazard assessment in the volcanic region of Mt. Etna (Italy): a probabilistic approach based on macroseismic data applied to volcano-tectonic seismicity, Bull. Earthq. Eng., 14, 1813-1825, 2016.

Azzaro, R., Barberi, G., D’Amico, S., Pace, B., Peruzza, L., and Tuvè, T.: When probabilistic seismic hazard climbs volcanoes: the Mt. Etna case, Italy - Part 1: Model components for sources parametrization, Nat. Hazards Earth Syst. Sci., 17, 1981-1998, https://doi.org/10.5194/nhess-17-1981-2017, 2017.
Barani, S. and Spallarossa, D.: Soil amplification in probabilistic ground motion hazard analysis, Bull. Earthq. Eng., 15, 25252545, https://doi.org/10.1007/s10518-016-9971-y, 2016.

Bindi, D., Pacor, F., Luzi, L., Puglia, R., Massa, M., Ameri, G., and Paolucci, R.: Ground motion prediction equations derived from the Italian strong motion database, Bull. Earthq. Eng., 9, 18991920, https://doi.org/10.1007/s10518-011-9313-z, 2011.

Boore, D. M.: Prediction of ground motion using the stochastic method, Pure Appl. Geophys., 160, 635-676, 2003.

Boore, D. M. and Atkinson, G. M.: Ground-motion prediction equations for the average horizontal component of PGA, PGV, and $5 \%$-damped PSA at spectral periods between $0.01 \mathrm{~s}$ and $100 \mathrm{~s}$, Earthquake Spectra, 24, 99-13, 2008.

Branca, S. and Ferrara, V.: The morphostructural setting of Mount Etna sedimentary basement (Italy): implications for the geometry and volume of the volcano edifice and its flank instability, Tectonophysics, 586, 46-64, https://doi.org/10.1016/j.tecto.2012.11.011, 2013.

Branca, S., Coltelli, M., and Groppelli, G.: Geological evolution of a complex basaltic stratovolcano: Mount Etna, Italy, Ital. J. Geosci., 130, 306-317, https://doi.org/10.3301/IJG.2011.13, 2011.

D’Amico, S., Meroni, F., Sousa, M. L., and Zonno, G.: Building vulnerability and seismic risk analysis in the urban area of Mt. Etna volcano (Italy), Bull. Earthq. Eng., 14, 2031-2045, 2016.

De Gori, P. and Chiarabba, C.: Qn structure of Mount Etna: Constraints for the physics of the plumbing system, J. Geophys. Res., 110, B05303, https://doi.org/10.1029/2003JB002875, 2005.

Giampiccolo, E., D’Amico, S., Patanè, D., and Gresta, S.: Attenuation and Source Parameters of Shallow Microearthquakes at Mt. Etna Volcano, Italy, Bull. Seismol. Soc. Am., 97, 184-197, https://doi.org/10.1785/0120050252, 2007.

Gruppo Analisi Dati Sismici: Catalogo dei terremoti della Sicilia Orientale - Calabria Meridionale (1999-2017), INGV, Catania http://sismoweb.ct.ingv.it/maps/eq_maps/sicily/catalogue.php, last access: 30 September 2017.

Herak, M.: ModelHVSR-A Matlab ${ }^{\circledR}$ tool to model horizontal-tovertical spectral ratio of ambient noise, Comput. Geosci., 34, 1514-1526, 2008.

Imperatori, W. and Mai, P. M.: The role of topography and lateral velocity heterogeneities on near-source scattering and ground-motion variability, Geophys. J. Int., 202, 2163-2181, https://doi.org/10.1093/gji/ggv281, 2015.

Joyner, W. B. and Boore, M.: Peak horizontal acceleration and velocity from strong-motion records including records from the 1979 Imperial Valley, California, earthquake, Bull. Seismol. Soc. Am., 71, 2011-2038, 1981.

Konno, K. and Ohmachi, T.: Ground-motion characteristics estimated from spectral ratio between horizontal and vertical components of microtremor, Bull. Seismol. Soc. Am., 88, 228-241, 1998.

Langer, H., Tusa, G., Scarfî, L., and Azzaro, R.: Ground-motion scenarios on Mt. Etna inferred from empirical relations and synthetic simulations, Bull. Earthq. Eng., 14, 1917-1943, 2016.

Lermo, J. and Chavez-Garcia, F. J.: Site effect evaluation using spectral ratios with only one station, Bull. Seismol. Soc. Am., 83, 1574-1594, 1993.

Lombardo, G., Langer, H., Gresta, S., Rigano, R., Monaco, C., and De Guidi, G.: On the importance of geolithologi- 
cal features for the estimate of the site response: the case of Catania metropolitan area (Italy), Nat. Hazards, 38, 339-354, https://doi.org/10.1007/s11069-005-0386-3, 2006.

Longo, E.: Seismic input modelling for relevant earthquakes in Eastern Sicily, PhD thesis, University of Malta, Malta, 190 pp., 2017.

Nakamura, Y.: A method for dynamic characteristics estimation of sub surface using microtremor on the surface, Railw. Tech. Res. Inst. Rep. 30, Railway Technical Research Institute, Tetsudo, Gijutsu, Kenkyujo, 25-33, 1989.

Nogoshi, M. and Igarashi, T.: On the amplitude characteristic of microtremor (part 2) (in Japanese with English abstract), J. Seismol. Soc. Jpn., 24, 26-40, 1971.

Ordaz, M., Martinelli, F., and D'Amico, V., and Meletti, C.: CRISIS2008: A flexible tool to perform probabilistic seismic hazard assessment, Seismol. Res. Lett., 84, 495-504, 2013.

Pace, B., Visini, F., and Peruzza, L.: FiSH: MATLAB tools to turn fault data into seismic hazard models, Seismol. Res. Lett., 87, 374-386, https://doi.org/10.1785/0220150189, 2016.

Panzera, F., Rigano, R., Lombardo, G., Cara, F., Di Giulio, G., and Rovelli, A.: The role of alternating outcrops of sediments and basaltic lavas on seismic urban scenario: the study case of Catania, Italy, Bull. Earthq. Eng., 9, 411-439, 2011.

Pagani, M., Monelli, D., Weatherill, G., Danciu, L., Crowley, H., Silva, V., Henshaw, P., Butler, L., Nastasi, M., Panzeri, L., Simionato, M., and Viganò, D.: OpenQuakeengine: An open hazard (and risk) software for the Global Earthquake Model, Seismol. Res. Lett., 85, 692-702, https://doi.org/10.1785/0220130087, 2014.

Panzera, F., Lombardo, G., and Muzzetta, I.: Evaluation of the buildings fundamental period through in-situ experimental techniques in the urban area of Catania, Italy, Phys. Chem. Earth, 63, 136-146, https://doi.org/10.1016/j.pce.2013.04.008, 2013.

Panzera, F., Lombardo, G., Monaco, C., and Di Stefano, A.: Seismic site effects observed on sediments and basaltic lavas outcropping in a test site of Catania, Italy, Nat. Hazards, 79, 1-27, https://doi.org/10.1007/s11069-015-1822-7, 2015.

Panzera, F., Sicali, S., Lombardo, G., Imposa, S., Gresta, S., and D'Amico, S.: A microtremor survey to define the subsoil structure in a mud volcanoes area: the case study of Salinelle (Mt. Etna, Italy), Environm. Earth Sci., 75, 1140, https://doi.org/10.1007/s12665-016-5974-x, 2016.

Panzera, F., Lombardo, G., Longo, E., Langer, H., Branca, S., Azzaro, R., Cicala, V., and Trimarchi, F.: Exploratory seismic site response surveys in a complex geologic area: a case study from Mt. Etna volcano (southern Italy), Nat. Hazards, 86, 385-399, https://doi.org/10.1007/s11069-016-2517-4, 2017.

Patanè, D., Ferrucci, F., and Gresta, S.: Spectral features of microearthquakes in volcanic areas: attenuation in the crust and amplitude response of the site at Mt. Etna, Italy, Bull. Seismol. Soc. Am., 84, 1842-1860, 1994.
Peruzza, L., Gee, R., Pace, B., Roberts, G., Scotti, O., Visini, F., Benedetti, L., and Pagani, M.: PSHA after a strong earthquake: hints for the recovery, Ann. Geophys., 59, 1-9, https://doi.org/10.4401/ag-7257, 2016.

Priolo, E.: 2-D spectral element simulation of destructive ground shaking in Catania (Italy), J. Seismol., 3, 289-309, 1999.

Rahpeyma, S., Halldorsson, B., Oliveira, C. S., Green, R. A., and Jónsson, S.: Detailed site effect estimation in the presence of strong velocity reversals within a small-aperture strongmotion array in Iceland, Soil Dynam. Earthq. Eng., 89, 136-151, https://doi.org/10.1016/j.soildyn.2016.07.001, 2016.

Saraò, A., Cocina, O., Moratto, L., and Scarfî, L.: Earthquake features through the seismic moment tensor, in: Project V3 - Multidisciplinary analysis of the relationships between tectonic structures and volcanic activity (Etna, Vulcano-Lipari system): Final Report (1 November 2014-30 June 2015), Agreement INGVDPC 2012-2021, Volcanological Programme 2012-2015, edited by: Azzaro R. and De Rosa, R., Miscellanea INGV, 29, 98-102, 2016.

Schnabel, P. B., Lysmer, J., and Seed, H. B.: Shake a computer program for earthquake response analysis of horizontally layered sites, Report No. EERC 72-12, Earthquake Engineering Research Center, University of California, Berkeley, California, 1972.

SESAME: Guidelines for the implementation of the $\mathrm{H} / \mathrm{V}$ spectral ratio technique on ambient vibrations: Measurements, processing and interpretation, SESAME European Research Project WP12, deliverable D23.12, availabe at: ftp://ftp.geo.uib.no/pub/seismo/SOFTWARE/SESAME/ USER-GUIDELINES/SESAME-HV-User-Guidelines.pdf (last access: 30 September 2017), 2004.

Sicali, S., Barbano, M. S., D’Amico, S., and Azzaro, R.: Characterization of seismicity at Mt. Etna volcano (Italy) by inter-event time distribution, J. Volcanol. Geoth. Res., 270, 1-9, 2014.

Stucchi, M., Meletti, C., Montaldo, V., Crowley, H., Calvi, G. M., and Boschi, E.: Seismic Hazard Assessment (2003-2009) for the Italian Building Code, Bull. Seismol. Soc. Am., 01, 1885-1911, https://doi.org/10.1785/0120100130, 2011.

Tusa, G. and Langer, H.: Prediction of ground-motion parameters for the volcanic area of Mount Etna, J. Seismol., 20, 1-42, https://doi.org/10.1007/s10950-015-9508-x, 2016.

Yokoyama, I.: The largest magnitudes of earthquakes associated with some historical volcanic eruptions and their volcanological significance, Ann. Geophys., 44, 1021-1029, 2001.

Zobin, V. M.: Seismic hazard of volcanic activity, J. Volcanol. Geoth. Res., 112, 1-14, 2001.

Zobin, V. M.: Introduction to Volcanic Seismology, 2nd Edn., Elsevier, Amsterdam, New York, Tokyo, 482 pp., 2012. 